\title{
Ampulla vaterinin primer taşlı yüzük hücreli karsinomu: Olgu sunumu ve literatür özeti
}

\author{
Primary signet ring cell carcinoma of ampulla of vater: Report of a case and a review \\ of the literature
}

Hatice Kuzular, Neşe Çallı Demirkan, Murat Özban

\section{Özet}

Ampulla vaterinin taşı yüzük hücreli karsinomu, adenokarsinomun nadir bir varyantıdır. Taşlı yüzük morfolojisindeki hücreler; intrasitoplazmik müsin içeren berrak sitoplazmalı, hiperkromatik, ekzantrik nükleuslu hücrelerdir. Bazı çalışmalarda immunohistokimyasal sonuçlara göre ampuller taşlı yüzük hücreli karsinom intestinal, pankreatobiliyer ve mikst tip olmak üzere üç subtipe ayrılmıştır. Bazı yayınlarda dördüncü tip olarak gastrik tipten de söz edilmektedir. Bu çalışmada 60 yaşında erkek hastada ampulla vateri yerleşimli taşlı yüzük hücreli karsinom olgusunu sunduk. Duodenum müsküler duvarını infiltre eden taşlı yüzük morfolojisindeki hücrelerde PAS-Alcian Blue ile intrasitoplazmik müsin birikimi tespit edildi. İmmunohistokimyasal incelemede taş।ı yüzük hücrelerinde MUC1, MUC2, CK19, CK20, CDX2 pozitif; CK7 fokal pozitif; MUC5AC yer yer zayıf pozitif saptandı. İntestinal tip ile ilişkili MUC2, CK20, CDX2 antikorlarının ve pankreatobiliyer tip ile ilişkili CK7, CK19, MUC1 antikorlarının bir arada pozitifliği nedeniyle olgu mikst tip ampulla vateri taşlı yüzük hücreli karsinomu lehine değerlendirildi ve literatür ışığında prognoz ve tedavi açısından tartışıldı.

Anahtar Kelimeler: Ampulla vateri, karsinom, taşlı yüzük hücresi.

Kuzular H, Çallı Demirkan N, Özban M. Ampulla Vaterinin Primer Taşlı Yüzük Hücreli Karsinomu: Olgu Sunumu ve Literatür Özeti. Pam Tıp Derg 2019;12:169-175.

\begin{abstract}
Signet ring cell carcinoma of the ampulla of vater is a rare variant of adenocarcinoma. Morphology of the signet ring cell carcinoma is defined as intracytoplasmic mucin, with clear cytoplasm and hyperchromatic, eccentric nucleus. It is divided into three subtypes as intestinal, pancreatobiliary and mixed type according to immunohistochemical findings. Gastric type is mentioned as the fourth type by other publications. In this study, signet ring cell carcinoma of ampulla vater in a 60 -year-old male patient is presented. Intracytoplasmic mucin accumulation was detected with PAS-Alcian Blue in cells that infiltrating the muscular wall of the duodenum. Immunohistochemically MUC1, MUC2, CK19, CK20, CDX2 positive; CK7 focal positive; MUC5AC locally weak positive detected in tumor cells. Because of coexistence MUC2, CK20, CDX2 antibodies associated with the intestinal type and CK7, CK19, MUC1 antibodies associated with pancreatobiliary type, the case was evaluated in favor of mixed type signet ring cell carcinoma of ampulla and discussed in terms of prognosis and treatment in the light of the literature.
\end{abstract}

Key Words: Ampulla of vater, carcinoma, signet ring cell.

Kuzular H, Çallı Demirkan N, Özban M. Primary signet ring cell carcinoma of ampulla of vater: Report of a case and a review of the literature. Pam Med J 2019;12:169-175.

Hatice Kuzular, Arş.Gör.Dr. Pamukkale Üniversitesi Tıp Fakültesi, Tıbbi Patoloji ABD, DENiZLí, e-posta:hkuzular@pau.edu.tr (orcid.org/0000-00030048-4247) (Sorumlu yazar)

Neşe Çallı Demirkan, Prof.Dr. Pamukkale Üniversitesi Tıp Fakültesi, Tıbbi Patoloji ABD, DENiZLİ, e-posta:ndemirkan@pau.edu.tr (orcid.org/00000001-5860-100X

Murat Özban, Doç.Dr. Pamukkale Üniversitesi Tıp Fakültesi, Genel Cerrahi ABD, DENiZLí, e-posta:mozban@pau.edu.tr (orcid.org/0000-00034974-8442) 


\section{Giriş}

Taşlı yüzük hücreli karsinomların (TYHK) \%90'ı midede gelişir [1, 2]; bütün gastrik kanserlerin \%15-30'unu oluşturur [3, 4]. Daha az olarak da safra kesesi, meme, pankreas, mesane ve kolonda ortaya çıkmaktadır [2]. Ampulla vaterinin primer TYHK oldukça nadir görülmekte ve tüm ampuller bölge tümörlerinin sadece \%4,9'unu oluşturmaktadır [5]. Ampulla vaterinin TYHKilk olarak Sekoguchi ve Mizumoto tarafından 1979 yılında tanımlanmıştır [6].

\section{Olgu}

Göğüs ağrısı ve sarılıkşikayetiyle dış merkeze başvuran 60 yaşında erkek hasta, yapılan Endoskopik retrograt kolanjiopankreatografi sonucunda ampulla vateri düzeyinde şüpheli lezyon izlenmesi üzerine genel cerrahi polikliniğine yönlendirildi. Hastanın yapılan tetkiklerinde total bilirubin: $9,64 \mathrm{mg} / \mathrm{dL}$, direkt bilirubin: 8,69 mg/dL, indirekt bilirubin: 0,95 mg/ $\mathrm{dL}$, CRP: $5,2 \mathrm{mg} / \mathrm{DI}$, Aspartat transaminaz: 146 IU/L, Alanin aminotransferaz: $221 \mathrm{IU} / \mathrm{L}$, Alkalen fosfataz: 656 IU/L, Gama glutamiltransferaz: $714 \mathrm{U} / \mathrm{L}$ saptandı. BT anjiografi'de intra ve ekstrahepatik safra yollarında ileri derecede dilatasyon, ampulla vateri düzeyinde duodenum lümenine polipoid uzanım gösteren $16 \mathrm{~mm}$ çapında tümöral dolum defekti görüldü. Abdomen Ultrasonografide koledok ve intrahepatik safra yollarında belirgin dilatasyon ve koledok distalinde malign duvar kalınlaşması izlendi. Hastaya pankreatoduodenektomi (PD), mide pilor rezeksiyonu ve kolesistektomiyi içeren whipple cerrahi prosedürü uygulandı.

Makroskopik olarak materyal $2,5 \times 2 \times 2 \mathrm{~cm}$ boyutlarında pilor, $15 \times 2,5 \times 2 \mathrm{~cm}$ boyutlarında duodenum, $9,5 \times 6,5 \times 4 \mathrm{~cm}$ boyutlarında pankreas ve $9 \times 4 \times 3 \mathrm{~cm}$ boyutlarında safra kesesinden oluşmaktaydı. Ampuller bölgede $1,6 \mathrm{~cm}$ çapında ince bağırsak lümenine doğru mukozada kabarıklığa neden olan, kesi yüzü kirli gri renkli solid nitelikte kitle lezyon görüldü.

Mikroskopik incelemede; tümörden hazırlanan kesitlerde hiperkromatik ekzantrik nükleuslu, berrak sitoplazmalı hücrelerin oluşturduğu diffüz infiltratif gelişim paterni sergileyen, duodenum müsküler duvarını infiltre eden malign epitelyal proliferasyon görüldü (Resim 1). Histokimyasal incelemede bu hücrelerde PAS-Alcian Blue ile intrasitoplazmik müsin birikimi izlendi
(Resim 2). İmmunohistokimyasal incelemede proliferasyonu oluşturan hücreler MUC1, MUC2, CK19, CK20, CDX2 pozitif; CK7 fokal pozitif; MUC5AC bazı tümör hücrelerinde zayıf (+) saptandı (Resim 3). Olgu hem intestinal tip ile ilişkili hem de pankreatobiliyer tip ile ilişkili immun belirteçlerin bir arada pozitifliği nedeniyle mikst tip TYHK olarak değerlendirildi.



Resim 1. İnce bağırsak duvarını diffüz olarak infiltre eden taşlı yüzük morfolojisinde malign epitelyal tümör (H\&E x40).

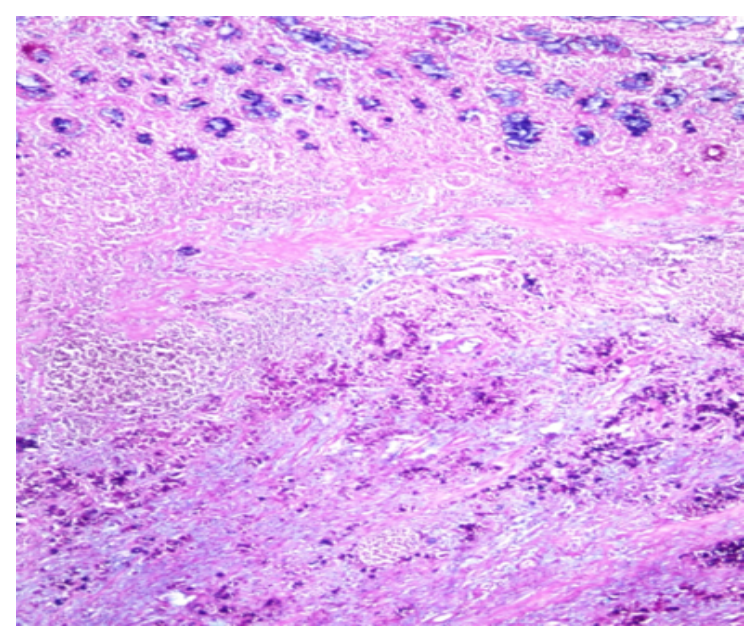

Resim 2. Tümöral infiltrasyonu oluşturan taşlı yüzük hücrelerinde $P A S-A B$ pozitif intrasitoplazmik müsin birikimi (PAS-AB x40). 


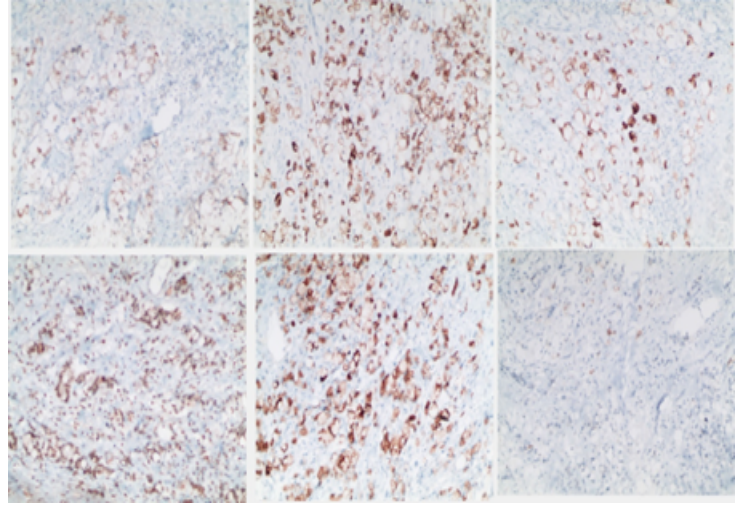

Resim 3. Taşlı yüzük hücrelerinde $\mathrm{CK} 7(\mathrm{~A})$, CK19 (B), CK20 (C), MUC1 (D), MUC2 (E), MUC5AC (F) ekspresyonu (DAB x100).

Periampuller bölge yerleşimli bir adet lenf nodunda tümör metastazı saptandı. Duktus sistikus çevresi ve çevre adipöz dokudan diseke edilen 5 adet lenf nodu reaktif olarak değerlendirildi. Tümörde lenfatik ve vasküler embolus izlenirken, perinöral invazyon saptanmadı. Bu bulgularla olgu WHO 2010 TNM evreleme sistemine göre T2N1Mx, Evre IIB olarak evrelendirildi.

Hastaya adjuvan gemsitabin ve sisplatinden oluşan kemoterapi ve radyoterapi uygulandı. Postoperatif 22. ayda olan hastanın aktif şikayeti, rekürrens ya da metastaz olmaksızın tedavisi devam etmektedir.

\section{Tartışma}

Ampulla vateri karsinomları tüm gastrointestinal sistem malignitelerinin sadece $\% 0,2$ 'sini; tüm periampuller bölge tümörlerinin ise \%6'sından azını oluşturmaktadır [5]. TYHK; tümörün \%50'den fazlasını intrasitoplazmik müsin içeren, hiperkromatik, ekzantrik nükleuslu, berrak sitoplazmalı taşı yüzük morfolojisindeki hücrelerin oluşturduğu adenokarsinom varyantı olarak tanımlanmıştı $[5,7]$. TYHK'nun ampulla vateride oldukça nadir görülmesi ve gastrointestinal sistemde en sık lokalizasyonun mide olması nedeniyle tümör kökeni konusunda iki teori öne sürülmüştür. İlk teori; TYHK'nun periampuller ektopik gastrik mukozadan gelişebileceği yönündedir $[8,9]$. Ramia ve ark. [8] TYHK ile infiltre ampulla kenarında duodenal mukozada küçük gastrik metaplazi odakları tespit etmiştir. Ishibashi ve ark. [9] ampulla vateride gastrik heterotopinin oldukça nadir görülmesi nedeniyle ampuller TYHK insidansının düşük olduğu görüşünü ileri sürmüşlerdir. Diğer teori; peptik ülserli hastalarda intralüminal artmış asiditeye karşı koruyucu yanıt olarak duodenal bulbusta gelişen gastrik tip metaplastik epitel alanlarından köken alabileceği yönündedir [8, 9]. Olgumuzun özgeçmişinde peptik ülser öyküsü mevcut değildir ve periampuller bölgeden alınan çok sayıdaki kesitte ektopik gastrik mukoza ya da gastrik tip metaplastik epitel saptanmamıştır.

Ampulla vaterinin TYHK ilk olarak Sekoguchi ve Mizumoto tarafından 1979 yılında tanımlanmıştır. Literatürde 1979 yılından günümüze kadar saptayabildiğimiz toplam 41 olgu yayınlanmıştır. Biz bu olguyla birlikte bilgilerine net olarak ulaşabildiğimiz 13 'ü kadın 10'u erkek 23 olguyu ele aldık. Bu olguların yaş aralığı 38-83; ortalama tanı yaşı 59 olarak saptanmıştır. Ortalama sağkalım 24 ay (6-90 ay) olarak tespit edilmiştir. Beş yıldan uzun sağkalım sadece 3 olguda bildirilmiştir $[3,5]$. TNM sınıflamasına göre 15 olgu ileri evre (T3, T4), 4 olgu erken evre (T2) de saptanmıştır. Sunduğumuz olgu erken evre (T2) olarak belirlenmiştir. Bilgilerine net olarak ulaşabildiğimiz 23 olgunun özellikleri Tablo 1'de belirtilmiştir.

Haddad ve ark. [10] ampuller karsinomların intestinal mukoza, distal koledok, distal pankreatik duktus veya Wirsung kanalını döşeyen epitelden ortaya çıktığını belirtmiştir. Farklı çalışmalarda ampulla vateri karsinomları histolojik olarak intestinal ve pankreatobiliyer tip olmak üzere ikiye ayrılmıştır [11].

Fischer ve Zhou [12] ampuller karsinomlarda CK20 (+), MUC2 (+), CK7 (-) immun profilini intestinal tip lehine; CK7 (+), CK20 (-) ve MUC2 (-) immun profilini pankreatobiliyer tip lehine değerlendirmiştir. Maekawa ve ark. [13] çalışmalarında CK7 (+), MUC2 (-) immun profiline sahip olguyu pankreatobiliyer tip lehine yorumlamıştır. Haddad ve ark. [10] MUC1 ve CK7 ekspresyonunu pankreatobiliyer tip; MUC2, CK20 ve CDX2 ekspresyonunu intestinal tip ile ilişkilendirmiştir. Ang ve ark. [14] ise intestinal ve pankreatobiliyer tip arasında CK7 ekspresyonu açısından anlamlı bir farklılık. Wen ve ark. [5] yaptıkları çalışmada immunohistokimyasal sonuçlara göre ampuller TYHK'nu intestinal, pankreatobiliyer, gastrik ve mikst (intestinal ve pankreatobiliyer epitelin bir arada bulunduğu) 
tip olarak 4 subtipe ayırmışlardır. CK7, CK19 ve MUC1 ekspresyonunu pankreatobiliyer tip; CK20, CDX2, MUC2 ekspresyonunu intestinal tip olarak değerlendirmiştir. İntestinal ve pankreatobiliyer tip ile ilişkili immun belirteçlerin negatif olduğu bir olguda MUC5AC, MUC6 koekspresyonunu gastrik tip lehine değerlendirmiş; MUC5AC ve MUC6 ekspresyonu ile gastrik tip ampuller TYHK arasında korelasyon olduğunu ileri sürmüştür. Çalışmalarında 8 olgunun 4'ünde MUC5AC ve MUC6 pozitifliği saptamış ve histolojik olarak periampuller heterotopik veya metaplastik gastrik mukoza tespit etmişlerdir. CK19, MUC2 ve MUC5AC pozitif bir olguyu mikst tip olarak değerlendirmişlerdir [5]. Sunduğumuz olguya ait immunohistokimyasal incelemede CK7, CK19, MUC1, MUC2, CK20, CDX2 ve MUC5AC pozitif saptandı. Pankreatobiliyer ve intestinal tip ile ilişkili immun belirteçlerin ekspresyonunun bir arada olması nedeniyle olgu ampulla vateri TYHK'nun mikst subtipi olarak değerlendirildi (Tablo 2). MUC5AC pozitif tespit edilmesine karşın gastrik diferansiyasyona rastlanmadı. Li ve ark. [15] literatürde ilk kez intramukozal taşlı yüzük hücreli komponenti bulunan ampulla vateri TYHK tanılı bir olgu bildirmişlerdir. Bizim olgumuzda alınan çok sayıda kesitte intramukozal tümör komponenti izlenmedi.

TYHK'nun ampulla dışı diğer gastrointestinal sistem lokalizasyonlarında prognozu kötü iken; literatürde yayınlanan ampuller TYHK tanılı olgu sayısı kısıtlı olduğu için prognoz net olarak belirlenememiştir [2, 8, 16]. Akatsu ve ark. [3] bir olguda cerrahi sonrası nodal invazyon ve rekürrens olmaksızın 7,5 yıl sağkalım bildirmiştir. Nodal invazyon olmayan olgularda küratif cerrahi rezeksiyonu takiben uzun dönem sağkalımın mümkün olabileceğini öne sürmüşlerdir. Wen ve ark. [5] iki olguda 5 yıldan uzun sağkalım bildirmiştir. $\mathrm{Bu}$ olgulardan biri intestinal tip, biri mikst tip olarak sınıflandırılmıştır. Kim ve ark. [17] ampuller karsinomlarda ileri T evresi, metastatik lenf nodu varlığı, az diferansiye tümör ve pankreatobiliyer tipin anlamlı kötü prognostik faktörler olduğunu tespit etmiştir. İntestinal tip TYHK'nun prognozunun pankreatobiliyer tipe göre daha iyi olduğu belirtilmiştir [11, 12, 18]. Bir çalışmada mikst tip TYHK'nun diğer tiplere göre prognozunun daha kötü olduğu ileri sürülmüştür [5]. Kimura [11] ve ark. ve Kim ve ark'nın [17] yaptıkları çalışmalarda lenf nodu metastazının intestinal tipe göre pankreatobiliyer tipte daha büyük oranda bulunduğu tespit edilmiştir. 18]. Zhou ve Schaefer [19] ise histopatolojik ve immunohistokimyasal subtiplerin klinik sonuçlar ile korele olmadığını öne sürmüştür. Bazı yayınlarda diğer tiplere göre daha kötü prognozlu olarak belirtilmesine rağmen mikst tip TYHK tanılı olgumuzda periampuller bölgede sadece 1 adet metastatik lenf nodu saptandı ve erken evre (T2) olarak belirlendi. İzlem süresince rekürrens ve uzak organ metastazı izlenmedi.

Literatürde bir olguda multipl pulmoner metastaz odakları [4], bir olguda kemik iliği ve akciğerde yaygın metastatik tümör odakları [20], bir olguda adjuvan kemoterapiyi takiben leptomeningeal metastaz [21], bir olguda erken dönemde gelişen kemik metastazı [22] ve 32 yaşındaki genç bir kadın hastada gelişen kemik iliği, vertebra, akciğer ve karaciğer metastazları [23] olmak üzere toplam 5 olguda uzak organ metastazı bildirilmiştir.

Ampulla vateri TYHK'nun tek küratif tedavi seçeneği cerrahi rezeksiyondur. Kabul gören genel tedavi yaklaşımı PD ya da ampullektomi olarak bildirilmiştir [24]. Illeri evre olgularda yaygın lenfadenektomi ve/veya parsiyel gastrektomi bu prosedüre eklenmektedir. Erken evre olgularda kürabiliteyi azaltmaksızın postoperatif komplikasyonları azaltmak amacıyla pilor koruyuculu pankreatoduodenektomi (PPPD) uygulanabileceği belirtilmiştir [25]. Paplomata ve ark. [21] PPPD uygulamış ve negatif tümör marjini sağlamışlardır. Bizim olgumuzda cerrahi öncesi tümör orjini net değerlendirilemediği için maksimum küratif tedavi için pilor rezeksiyonunu içeren pankreatoduodenektomi uygulanmış ve negatif tümör marjini elde edilmiştir.

Kemoradyoterapi küratif cerrahi rezeksiyon sonrası ek tedavi yöntemi olarak kullanılabilmektedir.Adjuvan kemoradyoterapiye rağmen cerrahi sonrası birçok olguda metastaz bildirildiği için sağkalıma katkısı net değildir [26]. Bazı çalışmalarda ise lenf nodu metastazı olmayan olgularda sağkalıma olumlu etkisi olmadığı belirtilmiştir [8]. Paplomata ve ark. [21] çalışmalarında ileri evre ampuller TYHK olgusuna gemsitabin-oksaliplatin tedavisi uygulanmasından 3 ay sonra leptomeningeal metastaz geliştiğini .

Sunduğumuz olguda periampuller bölgede 1 adet metastatik lenf nodu saptanması 
Tablo 1. Literatürde yayınlanan ampulla vateri taşlı yüzük hücreli karsinomlu olguların klinikopatolojik özellikleri

\begin{tabular}{|c|c|c|c|c|c|c|c|c|}
\hline Yazar & YII & Yaş & Cinsiyet & $\begin{array}{l}\text { Tümör } \\
\text { çapı }(\mathrm{cm})\end{array}$ & Evre & Tedavi & Takip (ay) & Sonuç \\
\hline $\begin{array}{l}\text { Nabeshima et al. } \\
\text { [20] }\end{array}$ & 2003 & 49 & Erkek & 0.8 & T3NxM1 & $\mathrm{KT}$ & 12 & Exitus \\
\hline Eriguchi et al. [25] & 2003 & 83 & Erkek & 1.5 & T3NOMO & PD & 18 & Hayatta \\
\hline Li et al. [15] & 2004 & 56 & Kadın & 1.5 & T2N1M0 & PD & 12 & Hayatta \\
\hline Ramia et al. [8] & 2004 & 67 & Kadın & 1.8 & T2NOMO & PD & 12 & Hayatta \\
\hline Akatsu et al. [3] & 2007 & 43 & Kadın & 2 & T2NOMO & PD & 90 & Hayatta \\
\hline Gao et al. [16] & 2009 & 38 & Kadın & 2 & T3NOMO & PD & 6 & Hayatta \\
\hline Ishibashi et al. [9] & 2009 & 59 & Kadın & 3 & T3NOMO & PD & 18 & Hayatta \\
\hline Taş ve ark. [4] & 2011 & 40 & Erkek & Bilinmiyor & TxN1M1 & Bilinmiyor & Bilinmiyor & Bilinmiyor \\
\hline Paplomata et al. [21] & 2011 & 45 & Kadın & 3 & T4pN1pMx & $P D+K T$ & 12 & Exitus \\
\hline Maekawa et al. [13] & 2011 & 75 & Erkek & 2 & T3NOMO & PD & 6 & Exitus \\
\hline $\begin{array}{l}\text { Lesquereux- } \\
\text { Martinez et al.[24] }\end{array}$ & 2012 & 78 & Kadın & 1.1 & TxN1M0 & $P D+K T$ & 14 & Hayatta \\
\hline Daoudi et al. [2] & 2012 & 55 & Erkek & Bilinmiyor & T3NOMO & $P D+K T$ & 8 & Hayatta \\
\hline Acharya et al. [7] & 2012 & 78 & Kadın & 3 & T3NOMO & PD & 6 & Hayatta \\
\hline Wen et al. [5] & 2014 & 40 & Kadın & 3 & T3NOMO & PD & 8 & Hayatta \\
\hline Wen et al. [5] & 2014 & 64 & Kadın & 6.5 & T4NxM0 & PD & 76 & Hayatta \\
\hline Wen et al. [5] & 2014 & 75 & Kadın & 3.5 & T4NxM0 & PD & 16 & Exitus \\
\hline Wen et al. [5] & 2014 & 62 & Erkek & 2.4 & TxN1M0 & PD & 27 & Exitus \\
\hline Wen et al. [5] & 2014 & 62 & Erkek & 3 & TxN1M0 & PD & 9 & Exitus \\
\hline Wen et al. [5] & 2014 & 53 & Erkek & 1.2 & T3NOMO & PD & 45 & Hayatta \\
\hline Wen et al. [5] & 2014 & 66 & Kadın & 1.5 & T3NOMO & PD & 54 & Hayatta \\
\hline Wen et al. [5] & 2014 & 68 & Erkek & 9.5 & T4NxM0 & PD & 72 & Hayatta \\
\hline Wakasugi et al. [26] & 2015 & 59 & Kadın & 2 & T3N1M1 & $P D+K T$ & 7 & Hayatta \\
\hline Olgumuz & 2018 & 60 & Erkek & 1.6 & T2N1M0 & $\begin{array}{l}\mathrm{PD}+\mathrm{KT} \\
+\mathrm{RT}\end{array}$ & 22 & Hayatta \\
\hline
\end{tabular}

KT: Kemoterapi; PD: Pankreatoduodenektomi; RT: Radyoterapi 
Tablo 2. Subtipler arasındaki immunohistokimyasal farklılıklar

\begin{tabular}{|c|c|c|c|c|c|c|c|c|c|}
\hline Yazar & YIl & CK7 & CK19 & CK20 & CDX2 & MUC1 & MUC2 & MUC5AC & Subtip \\
\hline Maekawa et al. [13] & 2011 & + & & - & Kısmi+ & + & - & & PB \\
\hline Acharya et al. [7] & 2012 & + & + & + & - & + & - & + & PB \\
\hline Wen et al. [5] & 2014 & - & + & - & - & - & - & $+/-$ & G \\
\hline Wen et al. [5] & 2014 & - & - & + & + & - & + & - & I \\
\hline Wen et al. [5] & 2014 & $+/-$ & + & - & - & + & - & $+/-$ & PB \\
\hline Wen et al. [5] & 2014 & + & + & - & - & + & - & + & PB \\
\hline Wen et al. [5] & 2014 & + & + & - & - & + & - & + & PB \\
\hline Wen et al. [5] & 2014 & + & + & - & - & $+/-$ & - & + & PB \\
\hline Wen et al. [5] & 2014 & + & + & - & - & $+/-$ & - & + & PB \\
\hline Wen et al. [5] & 2014 & - & + & - & - & - & + & + & $M$ \\
\hline Wakasugi et al. [26] & 2015 & + & + & + & + & & + & - & I \\
\hline Olgumuz & 2018 & Fokal+ & + & + & + & + & + & Zayıf + & M \\
\hline
\end{tabular}

PB:Pankreatobilier, G:Gastrik, I:Intestinal, M:Mikst

nedeniyle tedaviye adjuvan gemsitabinsisplatin kemoterapi ve radyoterapi eklenmiştir. Postoperatif 22. ayda olan hastanın aktif şikayeti, rekürrens ya da metastaz olmaksızın tedavisi devam etmektedir.

Çıkar İlişkisi: Yazarlar çıkar ilişkisi olmadığını beyan eder.

\section{Kaynaklar}

1. Yokota $T$, Kunii $Y$, Teshima $S$, et al. Signet ring cell carcinoma of the stomach: a clinicopathological comparison with the other histological types. Tohoku J Exp Med 1998;186:121-130.

2. Daoudi K, El Haoudi K, Bouyahia N, et al. Signet ring cell carcinoma of the vater's ampulla: A very rare malignancy. Case Rep Oncol Med 2012;2012:402798.

3. Akatsu T, Aiura K, Takahashi S, Kameyama K, Kitajima M, Kitagawa Y. Signet-ring cell carcinoma of the ampulla of vater: report of a case. Surg Today 2007;37:1110-1114.

4. Taş A, Ozer E, Köklü $S$, Kocak E. Signet ring cell carcinoma of the ampulla of vater: rare cause of acute pancreatitis. Scand J Gastroenterol 2011;46:126-127.

5. Wen X, Wu W, Wang B, Yao H, Teng X. Signet ring cell carcinoma of the ampulla of vater: immunophenotype and differentiation. Oncol Lett 2014;8:1687-1692.

6. Sekoguchi T, Mizumoto R. Clinicopathological study of papilla of vater. Geka Chiryo 1979;41:1-5.

7. Acharya MN, Panagiotopoulos N, Cohen P, Ahmad R, Jiao LR. Poorly-differentiated signet-ring cell carcinoma of the ampulla of vater: report of a rare malignancy. JOP 2013;14:190-194.

8. Ramia JM, Mansilla A, Villar J, Muffak K, Garrote D, Ferron JA. Signet-ring cell carcinoma of the vater's ampulla. JOP 2004;5:495-497.

9. Ishibashi $\mathrm{Y}$, Ito $\mathrm{Y}$, Omori K, Wakabayashi K. Signet ring cell carcinoma of the ampulla of vater: a case report. JOP 2009;10:690-693.

10. de Paiva Haddad LB, Patzina RA, Penteado S, et al. Lymph node involvement and not the histopathologic subtype is correlated with outcome after resection of adenocarcinoma of the ampulla of vater. J Gastrointest Surg 2010;14:719-728.

11. Kimura W, Futakawa N, Zhao B. Neoplastic diseases of the papilla of vater. J Hepatobiliary Pancreat Surg 2004;11:223-231.

12. Fischer HP, Zhou H. Pathogenesis of carcinoma of the papilla of vater. J Hepatobiliary Pancreat Surg 2004;11:301-309.

13. Maekawa H, Sakurada M, Orita H, Sato K. Signet-ring cell carcinoma co-existing with adenocarcinoma of the ampulla of vater. A case report. JOP 2011;12:162-166. 
14. Ang DC, Shia J, Tang LH, Katabi N, Klimstra DS. The utility of Immunohistochemistry in subtyping adenocarcinoma of the ampulla of vater. Am J Surg Pathol 2014;38:1371-1379.

15. Li L, Chen QH, Sullivan JD, Breuer FU. Signet-ring cell carcinoma of the ampulla of vater. Ann Clin Lab Sci 2004;34:471-475.

16. Gao JM, Tang SS, Fu W, Fan R. Signet-ring cell carcinoma of ampulla of vater: contrast-enhanced ultrasound findings. World J Gastroenterol 2009;15:888-891.

17. Kım WS, Choi DW, Choi SH, Heo JS, You DD, Lee HG. Clinical significance of pathologic subtype in curatively resected ampulla of vater cancer. J Surg Oncol 2012;105:266-272.

18. Kimura W, Futakawa N, Zhao B. Neoplastic diseases of the papilla of vater. J Hepatobiliary Pancreat Surg 2004;11:223-231.

19. Zhou H, Schaefer N, Wolff M, Fischer HP. Carcinoma of the ampulla of vater: comparative histologic/ immunohistochemical classification and follow-up. Am J Surg Pathol 2004;28:875-882.

20. Nabeshima S, Kishihara $Y$, Nabeshima A, et al. Poorly differentiated adenocarcinoma with signet-ring cells of the vater's ampulla, without jaundice but with disseminated carcinomatosis. Fukuoka Igaku Zasshi 2003;94:235-240.

21. Paplomata $E$, Wilfong L. Signet ring cell carcinoma of the ampulla of vater with leptomeningeal metastases: a case report. J Clin Oncol 2011;29:627-629.

22. Damania $R$, Weaver J, Cocieru A. Signet ring cell carcinoma of the ampulla of vater with early development of bone metastasis: Case report and review of the rare malignancy. J Gastrointest Cancer 2016;47:89-92.

23. Purohit RC, Kant K, Bhargava N, Kothari N, Purohit V. Signet ring cell carcinoma of ampulla of vater in a young adult. Indian J Gastroenterol 2005;24:222-223.

24. Lesquereux-Martínez L, Fernández Pérez A, Bustamante Montalvo M. Signet ring cell adenocarcinoma of the ampulla of Vater: a rare pathology. Rev Esp Enferm Dig 2012;104:501-502.

25. Eriguchi N, Aoyagi S, Jimi A. Signet-ring cell carcinoma of the ampulla of vater: report of a case. Surg Today 2003;33:467-469.

26. Wakasugi M, Tanemura M, Furukawa K, et al. Signet ring cell carcinoma of the ampulla of vater: Report of case and a review of the literature. Int J Surg Case Rep 2015;12:108-111. 